\title{
Legionella pneumophila Serogroup 1
}

National Cancer Institute

\section{Source}

National Cancer Institute. Legionella pneumophila Serogroup 1. NCI Thesaurus. Code C123498.

A subgroup of Legionella pneumophila differentiated by its antigenicity. Serogroup 1 is the serogroup most commonly associated with disease, responsible for $70-90 \%$ of cases of legionellosis. 